\title{
Arterial Stiffness: Recommendations and Standardization
}

\author{
Raymond R. Townsend \\ Perelman School of Medicine, University of Pennsylvania, Philadelphia, Pa., USA
}

\section{Key Words}

Pulse wave velocity $\cdot$ Central aortic pressure $\cdot$ Augmentation index $\cdot$ Chronic kidney disease

\begin{abstract}
The use of arterial stiffness measurements in longitudinal cohorts of normal populations, hypertensive patients, diabetic patients, healthy elderly, and patients on hemodialysis have confirmed the value of this important measure of arterial health, and established its complementary role to measures of blood pressure. Its contribution to understanding cardiovascular and mortality risk beyond blood pressure measurements has moved measures of arterial stiffness into the ranks of factors such as elevated cholesterol, diabetes, and left ventricular hypertrophy in considering cardiovascular risk. The recent international collaboration's publication of reference ranges for normal people and those with hypertension, along with the American Heart Association's recent scientific statement on standardizing arterial stiffness measurements are important aspects to consider in future studies employing these valuable methods, particularly as interventions that not only lower blood pressure but improve arterial function are tested in the clinical arena.

(C) 2016 S. Karger AG, Basel
\end{abstract}

\section{Introduction}

Incorporating a measurement such as arterial stiffness into clinical research and clinical care requires proficiency in performing such measurements, and knowledge of what the data derived during the measurement process mean to the clinical assessment and care of patients. More than a century of blood pressure measurements, and a panoply of intervention trials, have confirmed that properly done blood pressure measurements are a predictor of death and cardiovascular disease [1,2]. Guidelines in most parts of the world over the last 4 decades have placed blood pressure measurements into reference ranges (stages) based on age and 
Fig. 1. Shown on the y-axis is the frequency of 'arterial stiffness' in the title of publications found in PubMed. Shown on the $\mathrm{x}$-axis are the ranges of years in which the search term was found.

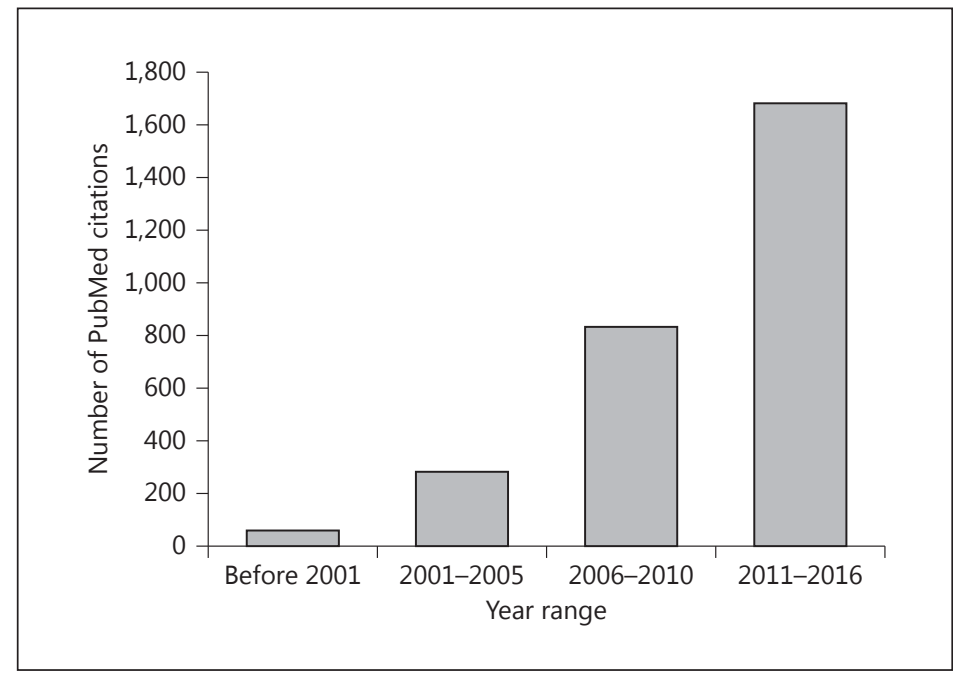

recommended goal blood pressure values when interventions to manage blood pressure are undertaken [1-4].

Noninvasive measures of arterial stiffness have been used in a number of cohorts over the last several decades as shown in figure 1. Until recently, the results were difficult to harmonize based upon the vascular territory studied and the methodology used to assess arterial stiffness. With the introduction of guidance for arterial stiffness measurements in 2006 in the European consensus document [5], the publication of international reference standards in 2010 [6], and the American Heart Association (AHA) scientific statement on arterial stiffness measurements in the USA [7] improved guidance is now available supporting greater uniformity in clinical studies and setting the stage for greater international collaborations as interventions which improve arterial stiffness are sought and studied in human populations.

The 2006 consensus document was the first publication to organize the approach to arterial stiffness, especially given the variety of approaches (tonometry, ultrasound, oscillometry, and magnetic resonance imaging) and the vascular territories studied. The main recommendations from this effort included a review of arterial stiffness physiology, measurement techniques, implications of arterial stiffness, and effects of medications [5].

In 2010, the normal and reference values for pulse wave velocity (PWV), the noninvasive gold standard for measuring arterial stiffness, were published [6]. This huge effort included nearly 17,000 subjects (about 1,500 were normal subjects) from several cohorts and provided decade-specific values for carotid-femoral PWV in normal people, and in those with hypertension. The recommendation from this report that clinical concern was warranted when carotid-femoral PWVs exceeded $12 \mathrm{~m} / \mathrm{s}$ was later modified by the artery research group of Europe to a value of $10 \mathrm{~m} / \mathrm{s}$ [8].

In 2015, the AHA published a scientific statement to encourage further standardization of arterial stiffness measurements incorporating input from researchers in Australia, Europe, Canada and the USA [7]. This statement reviewed the physiology behind the arterial stiffness measurements, the value that arterial stiffness brings into the clinical arena, the various methodologies used to assess PWV, how to assess new devices, considerations in measuring arterial stiffness in children, and an important segment on standardizing the procedural measurements. Particular recommendations are emphasized in the next section, and specific concerns that help standardize the measurement of PWV are reviewed in the section following that. 
Table 1. Standardizing PWV measurements

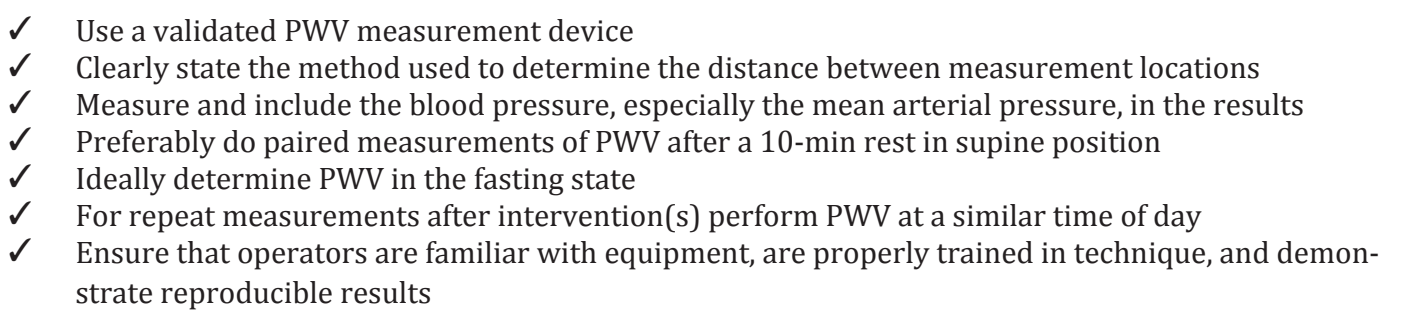

\section{Recommendations Regarding Measurement of Arterial Stiffness}

There are several methodologies that purport to reflect arterial stiffness. These include simple calculations of pulse pressure (systolic minus diastolic blood pressure [9]), regression formulae that evaluate the relative changes in diastolic pressure regressed onto the systolic pressure over $24 \mathrm{~h}$ (the ambulatory arterial stiffness index [10]), and the magnitude of increase in the systolic pressure profile in the aorta from pressure wave reflection (augmentation pressure or augmentation index [11]). While these indices reflect arterial stiffness to a degree, the best measure is either an invasive, or a noninvasive, determination of PWV, and this is recommended in the AHA scientific statement [7], as well as in the European expert consensus document [5].

Since it is possible to measure the PWV in any defined segment of the human circulation, or even estimate velocity from a single-point measurement, the question naturally arises: 'What pulse wave velocity measurement gives the most prediction for future outcomes?'. Both the consensus document [5] and the AHA scientific statement [7] recommend carotidfemoral PWV given the large preponderance of longitudinal data from cohort studies $[12,13]$. Other methods such as brachial-ankle PWV and the cardio-ankle vascular index also provide excellent cardiovascular prediction; however, their use in non-Asian populations is limited when compared with carotid-femoral PWV [14, 15].

The various technologies used to measure PWV include invasive pressure catheter measurements and noninvasive techniques such as oscillometry, tonometry, ultrasound and magnetic resonance imaging. These vary significantly in cost, time required to measure, and technical expertise required to undertake measurements, but all are considered as recommended methods to assess PWV [5, 7].

\section{Standardizing Arterial Stiffness Studies}

As with any technology with a period of rapid growth, the need for standardization of the techniques becomes evident, particularly as new investigators enter the field and seek guidelines for undertaking these studies. Both the consensus document and the AHA scientific statement stress the need to standardize the conditions under which PWV measurements are undertaken to ensure reliability within the investigation itself and generalizability to other groups undertaking similar measurements in different populations. Table 1 summarizes the issues in standardizing the PWV measurement procedure.

One of the most important aspects of PWV measurements is the inclusion of the mean arterial pressure. Interventions which lower mean arterial pressure also lower PWV. This does not mean that the arterial stiffness was 'improved' as a result of the intervention. It is 
important to show a reduction in PWV that exceeds that expected by a change in mean arterial pressure alone.

Standardizing validation methods for determining accuracy in new devices that measure arterial stiffness is also key to further enriching the PWV published database with quality studies. The guidelines from the Artery Society provide a framework for assessing PWV device measurement accuracy [16].

How distance is measured is equally important. The consensus document [5] and the AHA scientific statement [7] both recommend measuring the suprasternal notch to the carotid pulsation site, and the suprasternal notch to the femoral pulsation site (in millimeters), and then subtracting the carotid from the femoral distance. The importance of doing this properly, especially in overweight or obese individuals, has been stressed in recent literature [17].

\section{Conclusion}

Arterial stiffness measurements provide valuable predictive information for cardiovascular outcomes that complements standard risk factor assessments like blood pressure. Several guidance documents exist that provide direction for obtaining results that enable investigators to undertake studies that will provide both reliable data on arterial stiffness assessed in their own research, as well as ensure the ability to reproduce, or build upon, their findings in other venues and patient populations.

\section{Disclosure Statement}

Dr. Townsend has no relevant conflicts to disclose.

\section{References}

1 Mancia G, Fagard R, Narkiewicz K, Redon J, Zanchetti A, Bohm M, Christiaens T, Cifkova R, De BG, Dominiczak A, Galderisi M, Grobbee DE, Jaarsma T, Kirchhof P, Kjeldsen SE, Laurent S, Manolis AJ, Nilsson PM, Ruilope LM, Schmieder RE, Sirnes PA, Sleight P, Viigimaa M, Waeber B, Zannad F: 2013 ESH/ESC guidelines for the management of arterial hypertension: the task force for the management of arterial hypertension of the European Society of Hypertension (ESH) and of the European Society of Cardiology (ESC). J Hypertens 2013; 31:1281-1357.

2 James PA, Oparil S, Carter BL, Cushman WC, Dennison-Himmelfarb C, Handler J, Lackland DT, Lefevre ML, Mackenzie TD, Ogedegbe O, Smith SC Jr, Svetkey LP, Taler SJ, Townsend RR, Wright JT Jr, Narva AS, Ortiz E: 2014 evidence-based guideline for the management of high blood pressure in adults: report from the panel members appointed to the Eighth Joint National Committee (JNC 8). JAMA 2014;311:507-520.

3 Daskalopoulou SS, Rabi DM, Zarnke KB, Dasgupta K, Nerenberg K, Cloutier L, Gelfer M, Lamarre-Cliche M, Milot A, Bolli P, McKay DW, Tremblay G, McLean D, Tobe SW, Ruzicka M, Burns KD, Vallee M, Ramesh Prasad GV, Lebel M, Feldman RD, Selby P, Pipe A, Schiffrin EL, McFarlane PA, Oh P, Hegele RA, Khara M, Wilson TW, Brian PS, Burgess E, Herman RJ, Bacon SL, Rabkin SW, Gilbert RE, Campbell TS, Grover S, Honos G, Lindsay P, Hill MD, Coutts SB, Gubitz G, Campbell NR, Moe GW, Howlett JG, Boulanger JM, Prebtani A, Larochelle P, Leiter LA, Jones C, Ogilvie RI, Woo V, Kaczorowski J, Trudeau L, Petrella RJ, Hiremath S, Stone JA, Drouin D, Lavoie KL, Hamet P, Fodor G, Gregoire JC, Fournier A, Lewanczuk R, Dresser GK, Sharma M, Reid D, Benoit G, Feber J, Harris KC, Poirier L, Padwal RS: The 2015 Canadian Hypertension Education Program recommendations for blood pressure measurement, diagnosis, assessment of risk, prevention, and treatment of hypertension. Can J Cardiol 2015;31:549-568.

4 Weber MA, Schiffrin EL, White WB, Mann S, Lindholm LH, Kenerson JG, Flack JM, Carter BL, Materson BJ, Ram CV, Cohen DL, Cadet JC, Jean-Charles RR, Taler S, Kountz D, Townsend R, Chalmers J, Ramirez AJ, Bakris GL, Wang J, Schutte AE, Bisognano JD, Touyz RM, Sica D, Harrap SB: Clinical practice guidelines for the management of hypertension in the community a statement by the American Society of Hypertension and the International Society of Hypertension. J Hypertens 2014;32:3-15. 
Townsend et al.: Arterial Stiffness: Recommendations and Standardization

5 Laurent S, Cockcroft J, Van Bortel L, Boutouyrie P, Giannattasio C, Hayoz D, Pannier B, Vlachopoulos C, Wilkinson I, Struijker-Boudier H: Expert consensus document on arterial stiffness: methodological issues and clinical applications. Eur Heart J 2006;27:2588-2605.

6 Reference Values for Arterial Stiffness Collaboration: Determinants of pulse wave velocity in healthy people and in the presence of cardiovascular risk factors: 'establishing normal and reference values'. Eur Heart J 2010;31:2338-2350.

7 Townsend RR, Wilkinson IB, Schiffrin EL, Avolio AP, Chirinos JA, Cockcroft JR, Heffernan KS, Lakatta EG, McEniery CM, Mitchell GF, Najjar SS, Nichols WW, Urbina EM, Weber T: Recommendations for improving and standardizing vascular research on arterial stiffness: a scientific statement from the American Heart Association. Hypertension 2015;66:698-722.

8 Van Bortel LM, Laurent S, Boutouyrie P, Chowienczyk P, Cruickshank JK, De BT, Filipovsky J, Huybrechts S, Mattace-Raso FU, Protogerou AD, Schillaci G, Segers P, Vermeersch S, Weber T: Expert consensus document on the measurement of aortic stiffness in daily practice using carotid-femoral pulse wave velocity. J Hypertens 2012;30:445-448.

9 Chugh A, Bakris GL: Pulse pressure and arterial stiffness: an emerging renal risk predictor? J Hypertens 2007; 25:1796-1797.

10 Lakatta EG: Cardiovascular regulatory mechanisms in advanced age. Physiol Rev 1993;73:413-467.

11 Yasmin, Brown MJ: Similarities and differences between augmentation index and pulse wave velocity in the assessment of arterial stiffness. QJM 1999;92:595-600.

12 Vlachopoulos C, Aznaouridis K, Stefanadis C: Prediction of cardiovascular events and all-cause mortality with arterial stiffness: a systematic review and meta-analysis. J Am Coll Cardiol 2010;55:1318-1327.

13 Ben-Shlomo Y, Spears M, Boustred C, May M, Anderson SG, Benjamin EJ, Boutouyrie P, Cameron J, Chen CH, Cruickshank JK, Hwang SJ, Lakatta EG, Laurent S, Maldonado J, Mitchell GF, Najjar SS, Newman AB, Ohishi M, Pannier B, Pereira T, Vasan RS, Shokawa T, Sutton-Tyrell K, Verbeke F, Wang KL, Webb DJ, Hansen TW, Zoungas S, McEniery CM, Cockcroft JR, Wilkinson IB: Aortic pulse wave velocity improves cardiovascular event prediction: an individual participant meta-analysis of prospective observational data from 17,635 subjects. J Am Coll Cardiol 2014;63:636-646.

14 Horinaka S, Yagi H, Ishimura K, Fukushima H, Shibata Y, Sugawara R, Ishimitsu T: Cardio-ankle vascular index (CAVI) correlates with aortic stiffness in the thoracic aorta using ECG-gated multi-detector row computed tomography. Atherosclerosis 2014;235:239-245.

15 Ninomiya T, Kojima I, Doi Y, Fukuhara M, Hirakawa Y, Hata J, Kitazono T, Kiyohara Y: Brachial-ankle pulse wave velocity predicts the development of cardiovascular disease in a general Japanese population: the Hisayama Study. J Hypertens 2013;31:477-483.

16 Wilkinson IB, McEniery CM, Schillaci G, Boutouyrie P, Segers P, Donald A, Chowienczyk PJ: ARTERY Society guidelines for validation of non-invasive haemodynamic measurement devices: part 1 , arterial pulse wave velocity. Artery Res 2010;4:34-40.

17 Weber T, Ammer M, Rammer M, Adji A, O’Rourke MF, Wassertheurer S, Rosenkranz S, Eber B: Noninvasive determination of carotid-femoral pulse wave velocity depends critically on assessment of travel distance: a comparison with invasive measurement. J Hypertens 2009;27:1624-1630. 